\title{
Evaluation of energy and dietary intake estimates from a food frequency questionnaire using independent energy expenditure measurement and weighed food records
}

Monica H Carlsen*, Inger TL Lillegaard, Anette Karlsen, Rune Blomhoff, Christian A Drevon, Lene F Andersen

\begin{abstract}
Background: We have developed a food frequency questionnaire (FFQ) for the assessment of habitual diet, with special focus on the intake of fruit, vegetables and other antioxidant-rich foods and beverages. The aim of the present study was to evaluate the relative validity of the intakes of energy, food and nutrients from the FFQ.

Methods: Energy intake was evaluated against independent measures of energy expenditure using the ActiReg ${ }^{\circledR}$ system (motion detection), whereas 7-days weighed food records were used to study the relative validity of food and nutrient intake. The relationship between methods was investigated using correlation analyses and crossclassification of participants. The visual agreement between the methods was evaluated using Bland-Altman plots.

Results: We observed that the FFQ underestimated the energy intake by approximately $11 \%$ compared to the energy expenditure measured by the ActiReg ${ }^{\oplus}$. The correlation coefficient between energy intake and energy expenditure was 0.54 and $32 \%$ of the participants were defined as under-reporters. Compared to the weighed food records the percentages of energy from fat and added sugar from the FFQ were underestimated, whereas the percentage of energy from total carbohydrates and protein were slightly overestimated. The intake of foods rich in antioxidants did not vary significantly between the FFQ and weighed food records, with the exceptions of berries, coffee, tea and vegetables which were overestimated. Spearman's Rank Order Correlations between FFQ and weighed food records were 0.41 for berries, 0.58 for chocolate, 0.78 for coffee, 0.61 for fruit, 0.57 for fruit and berry juices, 0.40 for nuts, 0.74 for tea, 0.38 for vegetables and 0.70 for the intake of wine.

Conclusions: Our new FFQ provides a good estimate of the average energy intake and it obtains valid data on average intake of most antioxidant-rich foods and beverages. Our study also showed that the FFQs ability to rank participants according to intake of total antioxidants and most of the antioxidant-rich foods was good.
\end{abstract}

\section{Background}

Assessment of long-term dietary intake using methods of self-reporting has generally been associated with measurement errors [1]. Methods used challenges the participants' memory and ability to take into account the variability in intake, from day to day or by season. Because of the measurement errors, dietary assessment methods should always be validated before use. We have developed a new food frequency questionnaire (FFQ) for

\footnotetext{
* Correspondence: m.h.carlsen@medisin.uio.no

Department of Nutrition, Institute for Basic Medical Sciences, University of Oslo, Oslo, Norway
}

the assessment of habitual diet among adult Norwegians. In nutrition research FFQs are extensively used to investigate relationships between food intake and health [1]. Although the FFQ has inherent measurement errors, the FFQ designed to measure a person's habitual dietary intake over a defined period of time, is relatively inexpensive and easy to administer and is the exposure assessment tool of choice for large nutritional epidemiologic studies [1,2]. Our present semi-quantitative FFQ was developed for the assessment of habitual diet with special focus on the consumption of fruit, vegetables and other antioxidant-rich foods and beverages. 
Assessment of energy intake (EI) is crucial in any diet assessment, because all other nutrients are provided within the quantity of food needed to fulfill the energy requirement. Intake estimates of many foods and nutrients will be inaccurate if the EI is inaccurate. Thus, it is important to establish the FFQ's ability to assess EI when a new questionnaire is developed. The aims of the present study were to i) evaluate the EI from our new FFQ with an independent energy expenditure (EE) measurement; and ii) to assess the relative validity of the intakes of fruits, vegetables and other antioxidant-rich foods from the FFQ, using a 7-days weighed food record (WR) as reference method.

\section{Methods}

\section{Subjects and study design}

The evaluation study was designed to include a representative sample of the Norwegian population. The participants were recruited via mail to 4500 randomly selected women and men with home addresses in the Norwegian capital or surrounding area. The random selection of subjects was administered by The National Tax Office/Population Registration Office, and an equal number of men and women were invited, aged 18 to 80 years. Five hundred and four invited men and women (11\%) responded to the invitation. After interview screening 346 participants were enrolled in the study, of which 232 took part in the present part of the evaluation study. Exclusion criteria were pregnancy, weight loss of more than $5 \mathrm{~kg}$ during the last 6 months prior to the study and participation in other research projects. Data collection was carried out from September 2006 until October 2007. After recruitment the participants received the FFQ and written instructions by mail and were asked to fill in the FFQ at home. Within two weeks the participants attended a physical examination and returned the FFQ. Measurements of height and weight were performed by trained staff and the participants were lightly dressed with indoor clothes and without shoes when the anthropometric measures were taken. At the physical examination, the participants were randomly assigned to participate in either the assessment of EE ( $n=64)$, or to conduct the 7-days WR $(\mathrm{n}=168)$. The participants were given both oral and written instructions how to perform the tasks. The EE measurements and the 7-days WR were initiated 3 to 4 weeks after the participants filled in the FFQ. Social economic status of the participants was not assessed.

This study was conducted according to the guidelines laid down in the Declaration of Helsinki and all procedures involving human subjects were approved by the Regional Ethics Committee for Medical Research. Written informed consent was obtained from all subjects.

\section{The semi-quantitative food-frequency questionnaire}

The 14-page questionnaire was designed to capture the habitual food intake among Norwegian adults the preceding year. The FFQ was an extended and revised version of the semi-quantitative food-frequency questionnaire used in the Norwegian nation wide survey NORKOST 1997 (NFFQ). The original NFFQ was a validated, 180 items optical readable FFQ, developed to cover $100 \%$ of the total EI of the population [3-6]. Based on our extensive screening of antioxidant content in foods and beverages [7], the NFFQ was updated and revised with questions about food products and food categories assumed to be important sources of antioxidant intake in Norway. The new FFQ included 270 food items, grouped together according to the Norwegian meal pattern. Additional questions were added concerning intake of several food categories. In detail, 19 questions about berries, 4 questions about fruit, 6 questions about vegetables, 2 questions about chocolate, 3 questions about coffee and 2 questions about tea were added. Questions concerning the variable intake of berries due to seasonal variations were included. Furthermore, 10 questions were added about nuts and seeds and 27 questions about spices and herbs. The options of frequency of consumption of particular food items varied from several times a day to never/seldom, with portion sizes based on typical household units: slices, glasses, cups, pieces, spoons and teaspoons. When frequency was answered but not portion size, the food item was given the smallest portion size. When portion size was answered but not frequency, the food item was given the value zero. One participant was excluded from the study because a substantial amount of the questions in the FFQ were left unanswered. The dietary questions totaled 11 pages of the questionnaire whereas the last 3 pages were dedicated to questions concerning dietary supplements, smoking, physical activity and past and present illnesses and medication. The answered FFQs were scanned and the image files translated into data files using the Cardiff Teleform 2006 software.

\section{The energy study}

Sixty-four participants were randomly selected to carry out the EE measurements. The position-and-movements monitor ActiReg (PreMed AS, Oslo, Norway) was used to measure EE for 7 consecutive days. Two participants were excluded from the data analyses due to failure in the ActiReg ${ }^{\oplus}$ recording system and three were excluded due to measurement periods of less than 7 days. Thus, EE data from 59 participants were available for comparison with the EI estimated from the FFQ.

The ActiReg ${ }^{\circ}$ system uses a combined second-to-second recording of body position and motion to calculate EE [8]. The monitor has two pairs of position-and-motion sensors connected by cables to a battery-operated storage unit 
fixed to a waist belt. Each pair of sensors is attached by medical tape to the chest and the front of the right thigh, respectively. When the participants were sleeping, the ActiReg ${ }^{\circ}$ equipment was taken off and placed in a horizontal position. Collected data were transferred to a computer and processed by a dedicated program called ActiCalc ${ }^{\circ}[8]$. The ActiReg' system has been validated against both the doubly labeled water method and whole-body indirect calorimetry among young adults [8]. The validation studies demonstrated that there was no significant mean difference between EE measured by the ActiReg ${ }^{\circ}$ system and EE measured with indirect calorimetry or the doubly labeled water method [8]. The correlation coefficients between EE measured with the ActiReg ${ }^{\circ}$ system and EE measured with indirect calorimetry or the doubly label water method were 0.86 and 0.76 , respectively [9].

\section{The 7-days weighed food records study}

One hundred and sixty-eight participants were randomly selected to do the 7-days WR. Data from 21 participants were excluded from the analyses because less than 7 days had been recorded. The participants got written and oral instructions how to weigh and record all foods and beverages consumed in a food diary for 7 days, divided into 2 periods of 4 and 3 consecutive days, one week apart, including all days of a week. Each participant was provided with a food diary and a digital scale (Phillips HR 2393/95). The WRs were manually transcribed into data files which were imported into the KBS system. The WRs were distributed to the participants over a period of 7 months, from September to March, omitting the Christmas holidays.

\section{Food, nutrient and antioxidant databases}

Average daily intake of energy, nutrients and antioxidants from the FFQ and the WR were computed using the food database KBS AE-07 and KBS software system (KBS, version 4.9, 2008) developed at the Department of Nutrition, University of Oslo, Norway. The food database KBS AE07 is based on the 2006 edition of the Norwegian food composition table http://www.norwegianfoodcomp.no. The antioxidant values in KBS AE-07 are based on our extensive analyses of antioxidants in more than 3100 food samples procured worldwide $[7,10,11]$. The total antioxidant content in foods were measured using the FRAP (ferric-reducing ability of plasma) method and is expressed as $\mathrm{mmol} / 100 \mathrm{~g}$ sample $[7,10,11]$.

\section{Statistical methods}

Sample size calculation for the EI study was based on a SD of EI of $2 \mathrm{MJ}$ and a significance level of 0.05 with 80 percent power $[12,13]$. Thirty-two participants were required to detect a mean difference of $1 \mathrm{MJ}$ between EE measured with ActiReg ${ }^{\bullet}$ and EI assessed with the
FFQ. Height, weight, EE, EI, EI-EE and EI/EE were normally distributed and are presented as means and $95 \%$ confidence intervals (CI). Differences between EI and EE for all participants and between the genders were analyzed using paired and unpaired T-tests, respectively. All significance levels were two-sided. The visual agreement between the methods was analyzed as described by Bland and Altman $[14,15]$ using a plot of the differences between the two methods versus the average of the measurements. This type of plot shows the magnitude of disagreement, spot outliers and any trend. The relationship between EI and EE was investigated using Pearson product-moment correlation coefficient and by cross-classification of the participants into tertiles of $\mathrm{EE}$ and EI. The accuracy of the reported EI was calculated by expressing the ratio EI/EE, for which a value of 1 would mean complete agreement between EI and EE. Acceptable reporters (AR) were defined as having the ratio $\mathrm{EI} / \mathrm{EE}$ in the range of 0.80 to 1.20 , under-reporters (UR) as EI/EE < 0.80 and over-reporters (OR) as EI/EE $>1.20$. These definitions are partly based on the $95 \%$ confidence limits of agreement between EI and EE measured by the double labeled water method [16].

Chi-square tests for independence were conducted to assess if there was any difference in the distribution of men, women, smokers and non-smokers in UR and AR.

Percent energy from protein, fat and carbohydrates were normally distributed and are presented as means and SD. All micronutrient intakes and most food intake estimates were not normally distributed and data are therefore presented as median values with 25 and 75 percentiles. The differences between food intakes estimated by the FFQ and the WR were tested using Wilcoxon signed rank test (paired data). The relationship between the methods was analyzed using the Spearman rank correlation coefficient or the Pearson productmoment correlation coefficient and by classifying participants into quartiles of intake. Correctly classified participants were defined as participants categorized in the same quartile as defined by the WR estimate, whereas 'grossly misclassified' participants were defined as participants classified into opposite quartile. The accuracy of the estimated intakes was explored by expressing the ratio of estimates (FFQ/WR) for all nutrients and foods. Energy adjustment of intakes was calculated as absolute intake per $10 \mathrm{MJ}$. Results were considered to be statistically significant at $\mathrm{p}<0.05$. Data were analyzed using SPSS for Windows release 16.0 (SPSS Inc., Chicago, IL, USA).

\section{Results}

\section{Energy intake and energy expenditure estimates}

The 59 participants had a mean age of 44 (95\% CI $40,48)$ years. The mean EI from the FFQ was 
Table 1 Energy intake, energy expenditure and characteristics of participants in the energy study

\begin{tabular}{|c|c|c|c|c|c|c|c|c|c|c|c|c|}
\hline & \multicolumn{2}{|c|}{ All participants, $n=59$} & \multicolumn{2}{|c|}{ Men, $n=27$} & \multicolumn{2}{|c|}{ Women, $\mathrm{n}=32$} & \multicolumn{2}{|c|}{$U R, n=19$} & \multicolumn{2}{|c|}{$A R, n=35$} & \multicolumn{2}{|c|}{ OR, $n=5$} \\
\hline & Mean & $\mathrm{Cl}$ & Mean & $\mathrm{Cl}$ & Mean & $\mathrm{Cl}$ & Mean & $\mathrm{Cl}$ & Mean & $\mathrm{Cl}$ & Mean & $\mathrm{Cl}$ \\
\hline BMI (kg/m2) & 25.1 & $24.2,26.1$ & 26.3 & $25.1,27.5$ & 24.1 & $22.7,25.5$ & 26.1 & $24.0,28.2$ & 25.1 & $24.0,26.1$ & 21.7 & $18.2,25.2$ \\
\hline Current smokers (n) & 16 & & 9 & & 7 & & 5 & & 11 & & 0 & \\
\hline EE (MJ/day) & 11.1 & $10.5,11.8$ & 13.2 & $12.5,13.9$ & 9.4 & $9.0,9.9$ & 11.3 & $10.3,12.2$ & 11.2 & $10.3,12.1$ & 10.1 & $6.7,13.5$ \\
\hline El (MJ/day) & $9.8^{\mathrm{a}}$ & $9.0,10.6$ & $11.7^{\mathrm{b}}$ & $10.4,13.0$ & $8.3^{c}$ & $7.6,8.9$ & $7.3^{d}$ & $6.6,8.0$ & 10.5 & $9.7,11.3$ & 14.8 & $9.5,20.1$ \\
\hline El-EE (MJ/day) & -1.3 & $-2.0,-0.6$ & -1.5 & $-2.8,-0.22$ & -1.2 & $-2.0,-0.34$ & $-3.9^{d}$ & $-4.5,-3.4$ & -0.7 & $-1.2,-0.3$ & 4.7 & $2.2,7.2$ \\
\hline $\mathrm{El} / \mathrm{EE}$ & 0.89 & $0.83,0.96$ & 0.89 & $0.79,0.99$ & 0.90 & $0.81,0.99$ & $0.65^{d}$ & $0.62,0.68$ & 0.94 & $0.90,0.99$ & 1.46 & $1.29,1.64$ \\
\hline
\end{tabular}

Energy intake, El; energy expenditure, EE; under-reporters, UR; acceptable reporters, AR; over-reporters, OR. Data are presented as mean values with $95 \%$ confidence intervals (Cl). ${ }^{a}$ Different from $\mathrm{EE}, \mathrm{p}<0.001,(\mathrm{Cl}: 0.6 ; 2.0) ;{ }^{b}$ different from $\mathrm{EE}, \mathrm{p}=0.02,(\mathrm{Cl}: 0.3 ; 2.0) ;{ }^{c}$ different from $\mathrm{EE}, \mathrm{p}=0.007(\mathrm{Cl}$ : $0.2 ; 2.8)$. ${ }^{\mathrm{d}}$ Mean value different from $A R$ mean value, $p<0.01$.

significantly lower than the mean EE $(\mathrm{p}<0.01)$ (Table 1 ) and underestimated by $10.6 \%$ on average. The same difference between methods was observed for both men and women separately. The absolute mean difference between EI and EE was -1.3 (95\% CI, -2.0 to -0.6$) \mathrm{MJ} /$ day with $95 \%$ confidence limits of agreement $( \pm 1.96 \mathrm{SD}$ ) of -6.0 to $3.4 \mathrm{MJ} /$ day (Figure $1)$. The difference and the ratio of the two methods were of similar magnitude and did not differ significantly between the sexes (Table 1). The Pearson correlation coefficient between the two methods was 0.54. Cross-classification of all participants into tertiles with regard to EI and EE showed that 30 of the 59 participants $(51 \%)$ were classified in the correct tertile, whereas 26 participants (44\%) were classified in adjacent tertiles and three participants were misclassified by two tertiles.

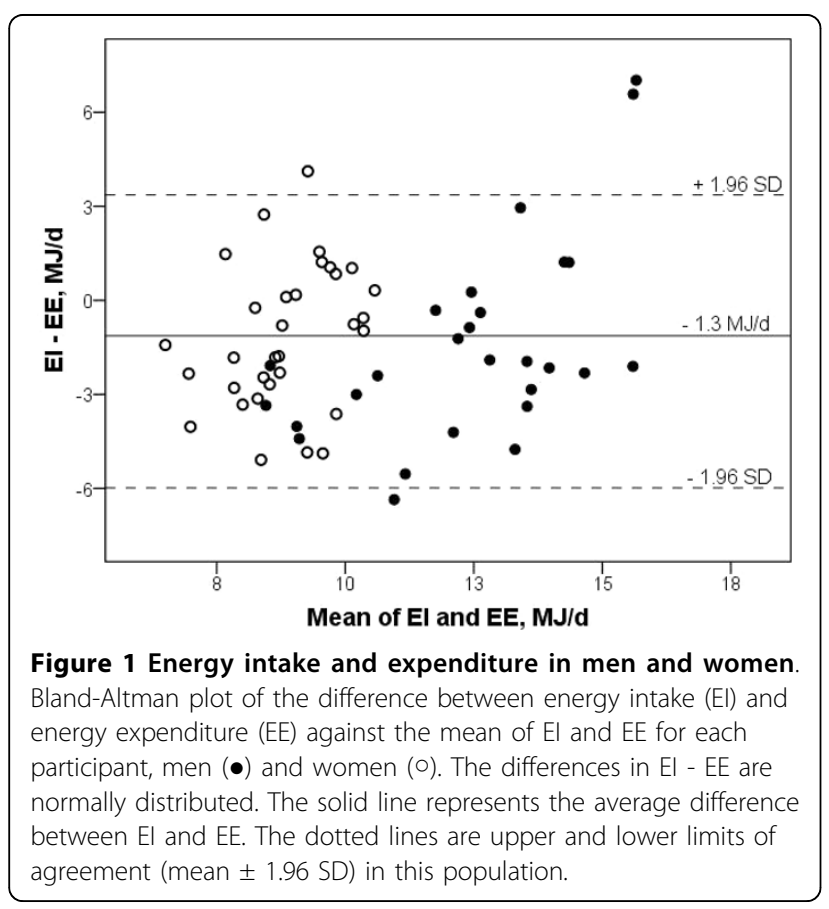

\section{Energy intakes among under-reporters and acceptable} reporters

Nineteen participants (32\%) were classified as UR (EI/EE $<0.80)$ and $35(59 \%)$ were classified as AR $(0.80<\mathrm{EI} / \mathrm{EE}$ $<1.20$ ) (Table 1). There were no significant differences in the distribution of men and women or smokers/nonsmokers in UR and AR ( $p=0.78$ and $p=0.13$, respectively). Moreover, BMI and age did not differ significantly between the groups $(p=0.69$ and $p=0.84$, respectively). EE was not significantly different ( $\mathrm{p}=$ 0.97) between UR and AR, whereas EI, absolute mean difference and the ratio of the methods were significantly different between UR and AR (all comparisons $\mathrm{p}$ $<0.01$, Table 1). UR underestimated their EI by on average $-35 \%$ compared to EE; the AR underreported their EI by on average $-6 \%$. The Pearson correlation coefficients between EI and EE were $r=0.85$ for UR as well as AR separately. The Bland-Altman plot of EI and EE for the UR and AR separately show a tendency of increasing under-reporting with increasing mean of EI and EE among the UR (Figure 2). The range defining the AR is relatively broad and if we use a more narrow range of 0.90 to 1.10 for EI/EE ratio, 17 participants would have been classified as AR.

In our study five participants were classified as OR (EI/EE > 1.20). OR overestimated their EI on average by $46 \%$, whereas BMI and EE did not differ significantly from AR. Due to their small number, no further analyses were done on the OR.

\section{Nutrient and food intake estimates in under-reporters and acceptable reporters}

UR had a lower percentage of energy derived from fat compared to AR ( $p<0.01)$, whereas the percentage of energy from protein was higher for UR than for AR $(p=0.01)$. No differences in percentage of energy from carbohydrates or added sugar were observed comparing UR and AR (Table 2). UR showed significantly lower absolute intake of vegetables compared to AR ( $\mathrm{p}=$ 0.03). There were no significant differences between UR and AR in the absolute intakes of berries, chocolate, 


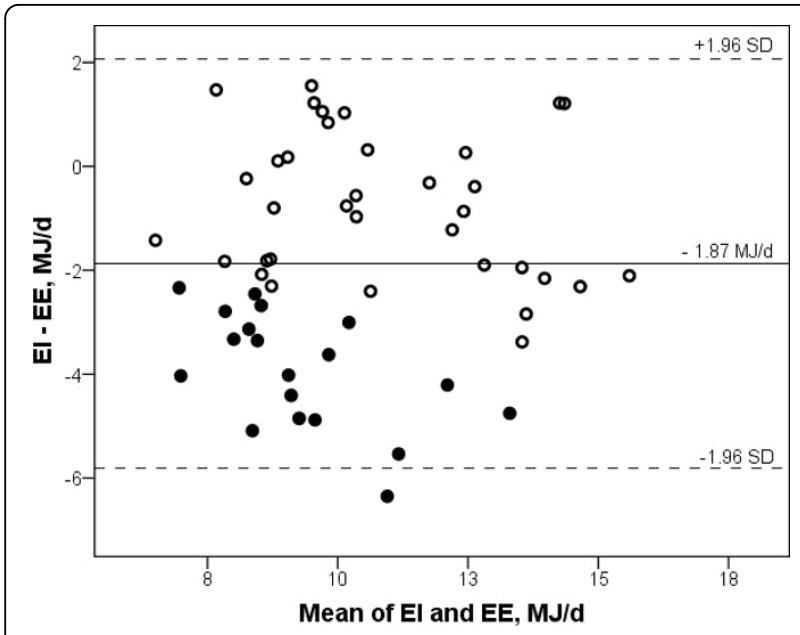

Figure 2 Energy intake and expenditure in under-reporters and acceptable reporters. Bland-Altman plot of the difference in energy intake (El) and energy expenditure (EE) against the mean of $\mathrm{El}$ and $\mathrm{EE}$, under-reporters $(\bullet)$ and acceptable reporters (O). The solid line represents the average difference between $\mathrm{El}$ and $\mathrm{EE}$. The dotted lines are upper and lower limits of agreement (mean \pm 1.96 $\mathrm{SD}$ ) in this population.

coffee, fruit, fruit and berry juices, nuts, tea and wine (Table 2). However, significantly lower absolute intakes of grain products, potatoes, meat, egg, dairy products and butter and margarine were observed for UR as compared to AR (under-reported 23, 30, 19, 50, 37 and 69\%, respectively, data not shown). When adjusted for EI, differences in food intakes between UR and AR were only observed for butter and fat $(\mathrm{p}=0.01$, under-reported $38 \%$ ). Total antioxidant intake was calculated based on total food intake from the FFQ and no significant difference was observed for the total antioxidant intakes of UR and AR ( $\mathrm{p}=0.14)$, whereas lower estimates were observed for $\beta$-carotene $(\mathrm{p}=0.04)$ and for vitamin $\mathrm{C}(\mathrm{p}$ $=0.02$ ) in UR as compared to AR (Table 2). With energy-adjustment there were no differences in intakes of antioxidants, $\beta$-carotene or vitamin $C$ between UR and AR (antioxidants: $\mathrm{p}=0.2 ; \beta$-carotene: $\mathrm{p}=0.6$; vita$\min C: \mathrm{p}=0.9)$.

\section{Relative validity of food and nutrient intakes}

For participants in the WR study, mean age was 48 (95\% CI 44, 52) years, mean BMI was 24.8 (95\% CI 24.2, 25.4) $\mathrm{kg} / \mathrm{m}^{2}$ and 28 were current smokers $(15$ men and 13 women). Total EI estimates were 9.1 and $9.4 \mathrm{MJ} /$ day, from the FFQ and WR respectively, and did not differ significantly $(\mathrm{p}=0.2)$. However, percent energy from added sugar, total carbohydrates, fat and protein all differed significantly between the FFQ and the WR (Table 3 ). The absolute intakes of $\beta$-carotene and vitamin $C$ were not significantly different between the two methods, whereas the antioxidant intake estimates were
Table 2 Percent energy from macronutrients and intakes of nutrients and foods among under-reporters and acceptable reporters

\begin{tabular}{|c|c|c|c|c|}
\hline \multirow[b]{3}{*}{ Percent energy from } & \multicolumn{2}{|c|}{ UR, $n=19$} & \multicolumn{2}{|c|}{$A R, n=35$} \\
\hline & Mean & SD & Mean & SD \\
\hline & & & & \\
\hline added sugar & 4 & 2.4 & 5 & 2.4 \\
\hline carbohydrates & 45 & 5.0 & 42 & 5.5 \\
\hline fat & $30^{a}$ & 6.2 & 35 & 5.3 \\
\hline protein & $18^{\mathrm{b}}$ & 2.4 & 17 & 2.0 \\
\hline Intakes of & Median & $\begin{array}{l}25^{\text {th }}, 75^{\text {th }} \\
\text { percentiles }\end{array}$ & Median & $\begin{array}{l}25^{\text {th }}, 75^{\text {th }} \\
\text { percentiles }\end{array}$ \\
\hline antioxidants (mmol/d) & 20 & 12,25 & 24 & 14,29 \\
\hline vitamin C (mg/d) & $118^{c}$ & 76,159 & 151 & 114,198 \\
\hline$\beta$-carotene $(\mathrm{mcg} / \mathrm{d})$ & $2^{d}$ & 1,3 & 3 & 2,4 \\
\hline berries $(g / d)$ & 13 & 1,29 & 19 & 10,30 \\
\hline chocolate $(\mathrm{g} / \mathrm{d})$ & 6 & 1,13 & 7 & 4,22 \\
\hline coffee $(\mathrm{g} / \mathrm{d})$ & 442 & 66,617 & 406 & 36,679 \\
\hline fruit $(g / d)$ & 121 & 69,221 & 113 & 66,181 \\
\hline fruit and berry juices $(\mathrm{g} / \mathrm{d})$ & 42 & 11,86 & 107 & 21,185 \\
\hline nuts (g/d) & 3 & 1,9 & 6 & 2,16 \\
\hline tea $(\mathrm{g} / \mathrm{d})$ & 80 & 20,400 & 60 & 20,220 \\
\hline vegetables $(\mathrm{g} / \mathrm{d})$ & $212^{\mathrm{e}}$ & 110,252 & 265 & 199,414 \\
\hline wine $(\mathrm{g} / \mathrm{d})$ & 66 & 12,119 & 43 & 3,89 \\
\hline
\end{tabular}

Under-reporters, UR; acceptable reporters, AR; standard deviation, SD. ${ }^{\text {a }}$ Different from AR, $p=0.003 ;^{b}$ different from $A R, p=0.012 ;^{c}$ different from $A R, p=0.024 ;{ }^{d}$ different from $A R, p=0.040 ;{ }^{e}$ different from $A R, p=0.027$

higher assessed by the FFQ than by the WR (Table 3 ). Spearman correlation coefficients for antioxidants, vitamin $C$ and $\beta$-carotene did all increase by 0.1 when energy adjusted (data not shown).

Estimated intakes of antioxidant-rich foods from the two methods, ratios and correlation coefficients are shown in Table 3. The intakes of berries, coffee and tea from the FFQ were higher than the intakes estimated from the WR (Table 3). No significant differences were observed for the absolute intakes of chocolate, fruit, fruit and berry juices, nuts or wine. Similar results were observed for energy-adjusted intakes (data not shown). Spearman correlation coefficients ranged from 0.40 for nuts to 0.78 for coffee (Table 3 ).

\section{Cross-classification of nutrient and food intake}

Classification of participants into quartiles of intake showed that approximately $80 \%$ of the participants were classified into correct or adjacent quartile when considering percent energy from macro nutrients (Table 4). For antioxidant-rich foods and beverages the fraction of participants classified into correct or adjacent category ranged from $74 \%$ for vegetable intake to $96 \%$ for coffee and tea intakes. Only $1 \%$ of the participants were grossly misclassified, for intakes of chocolate, coffee, fruits, nuts, 
Table 3 Percent energy from macronutrients and nutrients and food estimates from the FFQ and WR

\begin{tabular}{|c|c|c|c|c|}
\hline & FFQ & WR & Ratio FFQ/WR & Correlation $^{2}$ \\
\hline & Mean (SD) & Mean (SD) & Mean (SD) & \\
\hline \multicolumn{5}{|l|}{ Percent energy from } \\
\hline added sugar & $5(3.8)^{b}$ & $8(3.9)$ & $0.76(0.54)$ & $0.60^{c}$ \\
\hline carbohydrates & $44(6.1)^{b}$ & $42(6.8)$ & $1.06(0.16)$ & $0.51^{c}$ \\
\hline fat & $33(5.3)^{b}$ & $36(5.6)$ & $0.93(0.17)$ & $0.40^{c}$ \\
\hline protein & $17(2.4)^{b}$ & $16(2.9)$ & $1.08(0.17)$ & $0.55^{\mathrm{c}}$ \\
\hline Intakes of & Median (P25, P75) & Median (P25, P75) & Median (P25, P75) & \\
\hline antioxidants (mmol/d) & $20(15,28)^{d}$ & $18(12,24)$ & $1.16(0.94,1.57)$ & $0.60^{9}$ \\
\hline vitamin C (mg/d) & $136(102,178)$ & $128(88,179)$ & $1.12(0.72,1.82)$ & $0.29^{9}$ \\
\hline$\beta$-carotene $(\mathrm{mcg} / \mathrm{d})$ & $2402(1508,3519)$ & $2079(1225,3101)$ & $1.15(0.70,1.92)$ & $0.38^{9}$ \\
\hline berries $(g / d)$ & $21(13,32)^{d}$ & $11(3,24)$ & $1.55(0.83,3.25)$ & $0.41^{9}$ \\
\hline chocolate $(\mathrm{g} / \mathrm{d})$ & $7(2,17)$ & $8(0,22)$ & $0.63(0.32,1.91)$ & $0.58^{\mathrm{g}}$ \\
\hline coffee $(\mathrm{g} / \mathrm{d})$ & $380(89,645)^{\mathrm{e}}$ & $302(99,495)$ & $1.10(0.81,1.81)$ & $0.78^{9}$ \\
\hline fruit $(g / d)$ & $151(80,228)$ & $127(70,248)$ & $1.02(0.71,1.67)$ & $0.61^{9}$ \\
\hline fruit and berry juices $(\mathrm{g} / \mathrm{d})$ & $60(19,150)$ & $73(0,178)$ & $0.80(0.38,1.51)$ & $0.57^{9}$ \\
\hline nuts $(g / d)$ & $6(3,12)$ & $2(0,14)$ & $0.65(0.32,1.44)$ & $0.40^{9}$ \\
\hline tea $(g / d)$ & $90(20,400)^{f}$ & $80(0,298)$ & $1.05(0.55,1.80)$ & $0.74^{9}$ \\
\hline vegetables (g/d) & $243(166,322)^{d}$ & $162(118,222)$ & $1.39(1.01,2.03)$ & $0.38^{9}$ \\
\hline wine $(\mathrm{g} / \mathrm{d})$ & $45(14,106)$ & $48(0,114)$ & $0.96(0.46,1.49)$ & $0.70^{9}$ \\
\hline
\end{tabular}

Food frequency questionnaire, FFQ; weighed food record, WR; standard deviation, SD. $\mathrm{N}=147 .{ }^{\mathrm{a}}$ all correlations were significant at the 0.01 level; ${ }^{\mathrm{b}}$ different from

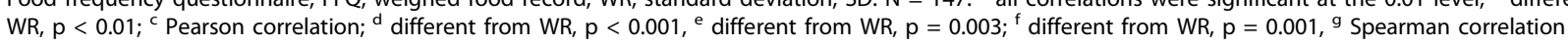

tea and wine, whereas $6 \%$ were grossly misclassified according to berry and vegetable intakes. Energy adjustment of food and nutrient estimates resulted in only small changes in classification (data not shown).

\section{Discussion}

\section{Evaluation of energy intake}

The present evaluation study shows that the FFQ underestimates the EI by $11 \%$. This level of underreporting is comparable to what was found in the validation study of the original NFFQ using doubly labelled water [5], and lower than what has been reported from some earlier European studies $[17,18]$. A Danish validation study using ActiReg ${ }^{\oplus}$ for EE assessment and a pre-coded food diary for EI assessment showed a similar degree of under-reporting [19]. The proportion of URs in our study (32\% of the participants) is slightly higher than reported from the EPIC study [17] but lower than what

Table 4 Cross-classification of subjects according to intake estimates

\begin{tabular}{lccc}
\hline & Classified correctly & Classified correctly or adjacent & Grossly misclassified by $\mathbf{3}$ categories \\
\hline \% energy from added sugar & 40 & 81 & 3 \\
\% energy from carbohydrates & 39 & 81 & 1 \\
\% energy from fat & 36 & 78 & 4 \\
\% energy from protein & 38 & 86 & 2 \\
Intakes of & & & 4 \\
antioxidants & 48 & 84 & 6 \\
vitamin C & 33 & 70 & 4 \\
$\beta$-carotene & 36 & 75 & 6 \\
berries & 37 & 78 & 1 \\
chocolate & 45 & 86 & 1 \\
coffee & 59 & 96 & 1 \\
fruits & 49 & 84 & 2 \\
fruit and berry juices & 44 & 86 & 1 \\
nuts & 44 & 82 & 1 \\
tea & 64 & 96 & 6 \\
vegetables & 39 & 74 & 1 \\
wine & 54 & 93 & \\
\hline Percnt & 54 & & \\
\end{tabular}

Percent of participants classified correctly, correctly and adjacent and grossly misclassified, respectively, according to percent energy form macro nutrients and intakes of antioxidants and antioxidant-rich foods and beverages, $n=147$. 
was reported from the OPEN study [18], and from an earlier national survey in Norway [20]. The tendency to under-report has in some studies been associated with body weight or BMI [21], but it is not confined to obese people and studies have shown that other factors like socio-demographic factors, lifestyle, psychosocial factors, education and characteristics of diet may be related to under-reporting [21-26]. These factors were not assessed in our present study. We found no evidence of association between body weight, smoking, BMI or EE and under-reporting in our present study.

Furthermore, in our study population including both men and women we observed a moderately high correlation coefficient between EE and EI, comparable to the study by Biltoft-Jensen and colleagues using ActiReg ${ }^{\bullet}$ as the reference method [19]. However, there was no correlation between EI and EE for women only. Our data showed that two women grossly over-reported their EI whereas 4 other women underreported their EI by more than $42 \%$. These outliers had a pronounced effect on the Pearson correlation coefficient and we speculate that including a higher number of female participants would have decreased the impact of these extreme reporters [27]. Excluding the 6 extreme reporters resulted in a correlation coefficient between EI and EE for the remaining women of $r=0.3$ (data not shown). In future studies employing the FFQ, it might be considered to exclude the 5\% highest under- and over reporters when food and nutrient intakes are estimated or subjects are to be ranked according to intake.

The correlations between EI and EE observed for UR and AR separately were similar and high, suggesting that the FFQ has good ability to rank participants according to EI, although the correlation independent of reporting category was hampered by the under-reporting of EI done by the UR. The fraction of participants classified into correct tertiles of EI showed that the FFQ had a satisfactory ability to rank participants in correct and adjacent tertiles, with less than $10 \%$ grossly misclassified. However, the FFQ showed a higher frequency of misclassification of EI among women than men.

\section{Nutrient and food intakes among under-reporters and acceptable reporters}

Comparison of EI against EE identifies bias only in reporting of EI. The identified underreporting raises questions as to whether the diet is underreported as a whole, or whether there is selective under-reporting of different foods leading to further bias in the reporting of nutrient intake. Studies among adults suggest that UR report low consumption of all food groups, but that the degree of under-reporting differs between foods perceived as healthy and unhealthy [20,28-32]. In earlier validation studies, UR showed a lower intake of fat and simple carbohydrates as compared with AR $[20,28,30,32]$. In our present study, UR showed lower percentage of energy from fat but not from added sugars or total carbohydrates, compared to AR. This corresponds to the observed low intakes of energy-dense foods like butter and margarine. The observed difference between UR and AR in intake of vegetables may have consequences for the absolute intakes of vitamin $C$ and $\beta$-carotene in UR, which were slightly but significantly lower than in AR. However, energy adjustment of the food intakes showed that the relative intake of antioxidant-rich foods were similar in UR and AR.

\section{Relative validity of nutrients, food and beverage intakes}

The 7-days WR is an open-ended dietary assessment method that captures more details and variation in the diet than the closed method of the FFQ [1]. In our present study the percentage of energy derived from added sugar and fat were lower in the FFQ than in the WR, whereas percentage of energy from total carbohydrates and protein were higher in the FFQ. The average intake of antioxidants was significantly overestimated by the FFQ whereas the correlation was high. The lower correlations observed for vitamin $C$ and $\beta$-carotene corresponded to the low correlation for vegetable and berry intake. Consumption of berries is often seasonal and over a year the intake may vary greatly. Although the FFQ included questions concerning berry intake within as well as outside berry season, the intake of berries showed pronounced degrees of over-reporting and misclassification. The individual WR recording periods were distributed from September through March. Not including the summer months, the typical strawberry season in Norway, could be a disadvantage and contribute to reduce the strength of the association between the FFQ and the WR berry intakes. Future dietary assessments using the FFQ should consider this tendency to overreport berry intake and correct for this in the estimates. However, for the other antioxidant-rich foods and beverages; chocolate, coffee, fruit, fruit and berry juices, nuts, tea and wine, the correlations between the two methods were good, especially for coffee, tea and wine, and the fraction of grossly misclassified participants were low. The intake of fruit, fruit juices and vegetables will be further evaluated using plasma and urine biomarkers.

\section{Strengths and limitations of the evaluation study}

Studies of the validity of FFQs are often difficult to carry out due to the difficulties of obtaining a sufficiently large and representative sample of the population to which the FFQ may be applied, and the lack of a 'gold standard' reference method. The participants in our study were recruited from a restricted geographical area 
of the country and only $11 \%$ of those invited responded, suggesting that the study population was biased towards motivated subjects. The age distribution in the present study population was comparable to the distribution of age in this area (Statistics Norway, SSB august 2009, http://www.ssb.no/). There were only small deviations in relation to gender and smoking; our study population had more women $(2 \%)$ and fewer smokers (3\%) than the average for this geographical area of Norway. Moreover, local dietary variations throughout the country may suggest that the inhabitants of the Norwegian capital and surrounding area may not be representative of the general Norwegian population with regard to habitual diet. Sample size calculations were performed based on the ability to detect differences in intake and not based on correlation estimations. Thus, the sample sizes of the genders separately were too small to detect correlations below 0.47 .

Prolonged recording like 7-days WR can lead to misreporting of food intakes because the recording itself may be too demanding for the participants [33], resulting in changes in behavior and dietary intake [34]. Moreover, the list of food items in the FFQ may not cover a participant's habitual diet whereas the WR may not capture the habitual intake of foods consumed sporadically because it does not cover the same time period as the FFQ. Misreporting of food intake will promote attenuation of the correlation between the FFQ and the reference method [1]. One of the strengths of our present study is that we used an objective instrument as reference method to measure EE. The ActiReg system has been validated, demonstrating no significant difference between EE measured with ActiReg $^{\oplus}$ and EE measured with double labeled water or indirect calorimetry [8]. However, ActiReg ${ }^{\ominus}$ shows considerable variation at the individual level. Certain types of arm work, carrying loads and water activities are not well accounted for due to the design of the instrument. Moreover, conclusions about the validity of the FFQ EI estimates can only be drawn if two underlying assumptions hold true: that the participants are in energy balance and that the short term EE measurement represents the habitual and usual EE. In our present study EE was measured using the ActiReg ${ }^{\circledR}$ system during 7 consecutive days. Fluctuations in energy balance during these 7 days were not assessed, thus we can only assume the participants were in energy balance during this period. With respect to the second assumption there was only one 7-days EE measurement period, whereas the FFQ was designed to assess usual dietary intake over the preceding year. The observed discrepancies between EE and EI might therefore partly be explained by the incomplete coverage of the FFQ data by the ActiReg ${ }^{\bullet}$ measurement period.
The implications of the errors in energy, food and nutrient intakes identified in our present study will have attenuating effects on the risk assessments in future epidemiological studies employing the FFQ [1], and may require increased sample size due to reduction in power [35].

\section{Conclusions}

In conclusion, our new FFQ provides a good estimate for the average EI, underestimating the EI by $11 \%$ as compared to the EE and by $5 \%$ as compared to the WR. The ability of the FFQ to assess average intakes of antioxidant-rich foods and beverages was for most items good. The FFQ's ability to rank participants according to intake of total antioxidants and most of the antioxidant-rich foods was also good.

\section{List of abbreviations}

FFQ: Food Frequency Questionnaire; NFFQ: NORKOST food frequency questionnaire; EE: energy expenditure; EI: energy intake; BMI: body mass index; WR: weighed food record; UR: under-reporters; AR: acceptable reporters; OR: over-reporters; SD: standard deviation.

\section{Acknowledgements}

The authors would like to thank Elin Bjørge Løken and Jannicke Fredriksen for assistance with the Food Database AE-07, Anne Randi Enget and Kari Holte for excellent technical assistance and Gunnar Åmlid for valuable help with the Cardiff Teleform 2006 Software. This work was funded by the Throne Holst foundation, The Research Council of Norway, Freia Medical Research Fund and the Norwegian Cancer Society.

\section{Authors' contributions}

MHC was responsible for study design, design of the FFQ, recruitment, data collection, statistical analyses and preparation of manuscript. ITLL contributed to study design, data collection, statistical analyses and manuscript revision, AK contributed to study design, recruitment, data collection and manuscript revision, RB was responsible for funding, study design and manuscript revision, CAD contributed to study design and manuscript revision and LFA contributed to study design, design of the FFQ, statistical analyses and manuscript revision. All authors read and approved the final manuscript.

\section{Competing interests}

$\mathrm{RB}$ and $\mathrm{CAD}$ are shareholders in Vitas AS. The other authors declare that they have no competing interests.

Received: 10 February 2010 Accepted: 15 September 2010 Published: 15 September 2010

\section{References}

1. Willett W: Nutritional Epidemiology Oxford: Oxford University Press 1998.

2. Willett WC, Hu FB: Not the time to abandon the food frequency questionnaire: point. Cancer Epidemiol Biomarkers Prev 2006, 15:1757-1758.

3. Johansson L, Solvoll K, Drevon CA: Dietary habits among Norwegian men and women. Scandinavian Journal of Nutrition 1997, 41:63-70.

4. Nes M, Andersen LF, Solvoll K, Sandstad B, Hustvedt BE, Løvø A, Drevon CA: Accuracy of a quantitative food frequency questionnaire applied in elderly Norwegian women. Eur J Clin Nutr 1992, 46:809-821.

5. Andersen LF, Tomten $H$, Haggarty $P$, Lovo A, Hustvedt BE: Validation of energy intake estimated from a food frequency questionnaire: a doubly labelled water study. Eur J Clin Nutr 2003, 57:279-284. 
6. Andersen LF, Solvoll K, Johansson LR, Salminen I, Aro A, Drevon CA: Evaluation of a food frequency questionnaire with weighed records, fatty acids, and alpha-tocopherol in adipose tissue and serum. Am J Epidemiol 1999, 150:75-87.

7. Carlsen MH, Halvorsen BL, Holte K, Bohn SK, Dragland S, Sampson L, Willey C, Senoo H, Umezono Y, Sanada C, Barikmo IE, Berhe N, Willett WC, Phillips KM, Jacobs DR Jr, Blomhoff R: The total antioxidant content of more than 3100 foods, beverages, spices, herbs and supplements used worldwide. Nutr J 2010, 9:3.

8. Hustvedt BE, Christophersen A, Johnsen LR, Tomten H, McNeill G, Haggarty P, Lovo A: Description and validation of the ActiReg: a novel instrument to measure physical activity and energy expenditure. $\mathrm{Br} J$ Nutr 2004, 92:1001-1008.

9. Lillegaard IT, Andersen LF: Validation of a pre-coded food diary with energy expenditure, comparison of under-reporters $v$. acceptable reporters. Br J Nutr 2005, 94:998-1003.

10. Halvorsen BL, Carlsen MH, Phillips KM, Bohn SK, Holte K, Jacobs DR Jr, Blomhoff R: Content of redox-active compounds (ie, antioxidants) in foods consumed in the United States. Am J Clin Nutr 2006, 84:95-135.

11. Halvorsen BL, Holte K, Myhrstad MCW, Barikmo I, Hvattum E, Remberg SF, Wold AB, Haffner K, Baugerod H, Andersen LF, Moskaug JO, Jacobs DR, Blomhoff R: A systematic screening of total antioxidants in dietary plants. Journal of Nutrition 2002, 132:461-471.

12. Cole TJ: Sampling, study size and power. In Design concepts in Nutritional Epidemiology. Edited by: Margetts BM, Nelson M. Oxford: Oxford University Press; , 2 1997:64-86.

13. Aalen OO: How to plan studies. Innføring i statistikk Oslo: Gyldendal Norsk Forlag AS 2005.

14. Bland JM, Altman DG: Measuring agreement in method comparison studies. Stat Methods Med Res 1999, 8:135-160.

15. Bland JM, Altman DG: Statistical methods for assessing agreement between two methods of clinical measurement. The Lancet 1986, 8:307-310.

16. Black AE: The sensitivity and specificity of the Goldberg cut-off for El: BMR for identifying diet reports of poor validity. Eur J Clin Nutr 2000, 54:395-404.

17. Kroke A, Klipstein-Grobusch K, Voss S, Moseneder J, Thielecke F, Noack R, Boeing $\mathrm{H}$ : Validation of a self-administered food-frequency questionnaire administered in the European Prospective Investigation into Cancer and Nutrition (EPIC) Study: comparison of energy, protein, and macronutrient intakes estimated with the doubly labeled water, urinary nitrogen, and repeated 24-h dietary recall methods. Am J Clin Nutr 1999, 70:439-447.

18. Subar AF, Kipnis V, Troiano RP, Midthune D, Schoeller DA, Bingham S, Sharbaugh CO, Trabulsi J, Runswick S, Ballard-Barbash R, Sunshine J, Schatzkin A: Using intake biomarkers to evaluate the extent of dietary misreporting in a large sample of adults: the OPEN study. Am J Epidemiol 2003, 158:1-13.

19. Biltoft-Jensen A, Matthiessen J, Rasmussen LB, Fagt S, Groth MV, Hels O: Validation of the Danish 7-day pre-coded food diary among adults: energy intake $v$. energy expenditure and recording length. $\mathrm{Br} J$ Nutr 2009, 1-9.

20. Johansson L, Solvoll K, Bjørneboe G-E, Drevon CA: Under- and overreporting of energy intake related to weight status and lifestyle in a nationwide sample. Am J Clin Nutr 1998, 68:266-274.

21. Hill RJ, Davies PS: The validity of self-reported energy intake as determined using the doubly labelled water technique. Br J Nutr 2001, 85:415-430,

22. Rasmussen $L B$, Matthiessen J, Biltoft-Jensen A, Tetens I: Characteristics of misreporters of dietary intake and physical activity. Public Health Nutr 2007, 10:230-237.

23. Braam LA, Ocke MC, Bueno-de-Mesquita HB, Seidell JC: Determinants of obesity-related underreporting of energy intake. Am J Epidemiol 1998, 147:1081-1086.

24. Johansson G, Wikman A, Ahren AM, Hallmans G, Johansson I: Underreporting of energy intake in repeated 24-hour recalls related to gender, age, weight status, day of interview, educational level, reported food intake, smoking habits and area of living. Public Health Nutr 2001, 4:919-927.
25. Trabulsi J, Schoeller DA: Evaluation of dietary assessment instruments against doubly labeled water, a biomarker of habitual energy intake. Am J Physiol Endocrinol Metab 2001, 281:E891-E899.

26. Tooze JA, Subar AF, Thompson FE, Troiano R, Schatzkin A, Kipnis V: Psychosocial predictors of energy underreporting in a large doubly labeled water study. Am J Clin Nutr 2004, 79:795-804.

27. Masson LF, McNeill G, Tomany JO, Simpson JA, Peace HS, Wei L, Grubb DA, Bolton-Smith C: Statistical approaches for assessing the relative validity of a food-frequency questionnaire: use of correlation coefficients and the Kappa statistic. Public Health Nutr 2002, 6:313-321.

28. Bingham SA, Cassidy A, Cole TJ, Welch A, Runswick SA, Black AE, Thurnham D, Bates C, Khaw KT, Key TJ: Validation of weighed records and other methods of dietary assessment using the $24 \mathrm{~h}$ urine nitrogen technique and other biological markers. Br J Nutr 1995, 73:531-550.

29. Pryer JA, Vrijheid M, Nichols R, Kiggins M, Elliott P: Who are the 'low energy reporters' in the dietary and nutritional survey of British adults? Int J Epidemiol 1997, 26:146-154.

30. Cook A, Pryer J, Shetty P: The problem of accuracy in dietary surveys. Analysis of the over 65 UK National Diet and Nutrition Survey. $J$ Epidemiol Community Health 2000, 54:611-616.

31. Krebs-Smith SM, Graubard BI, Kahle LL, Subar AF, Cleveland LE, BallardBarbash R: Low energy reporters vs others: a comparison of reported food intakes. Eur J Clin Nutr 2000, 54:281-287.

32. Lafay L, Mennen L, Basdevant A, Charles MA, Borys JM, Eschwege E, Romon M: Does energy intake underreporting involve all kinds of food or only specific food items? Results from the Fleurbaix Laventie Ville Sante (FLVS) study. Int J Obes Relat Metab Disord 2000, 24:1500-1506.

33. Kristjansdottir AG, Andersen LF, Haraldsdottir J, de A, Thorsdottir I: Validity of a questionnaire to assess fruit and vegetable intake in adults. Eur J Clin Nutr 2006, 60:408-415.

34. Cade J, Thompson R, Burley V, Warm D: Development, validation and utilisation of food-frequency questionnaires - a review. Public Health Nutr 2002, 5:567-587.

35. Keown-Eyssen GE, Tibshirani R: Implications of measurement error in exposure for the sample sizes of case-control studies. Am J Epidemiol 1994, 139:415-421.

doi:10.1186/1475-2891-9-37

Cite this article as: Carlsen et al: Evaluation of energy and dietary intake estimates from a food frequency questionnaire using independent energy expenditure measurement and weighed food records. Nutrition Journal 2010 9:37.

\section{Submit your next manuscript to BioMed Central and take full advantage of:}

- Convenient online submission

- Thorough peer review

- No space constraints or color figure charges

- Immediate publication on acceptance

- Inclusion in PubMed, CAS, Scopus and Google Scholar

- Research which is freely available for redistribution

Submit your manuscript at www.biomedcentral.com/submit
Biomed Central 